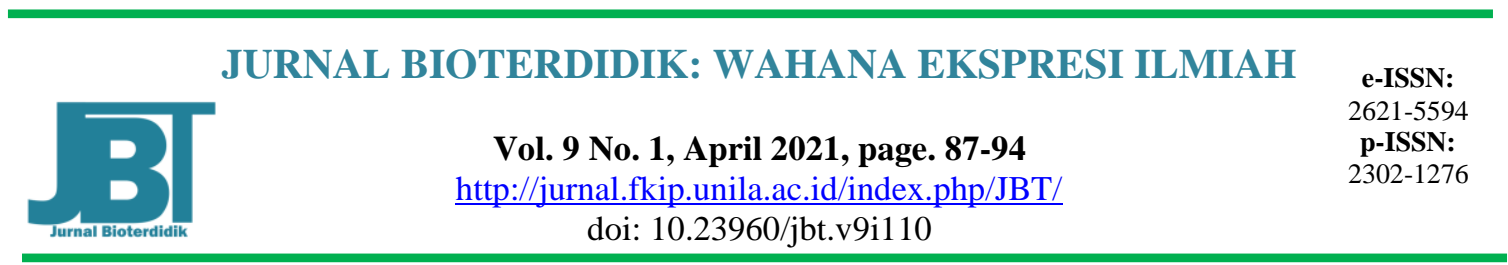

\title{
Hubungan Antara Fleksibilitas Kognitif Dengan Keterampilan Pemecahan Masalah Pada Mata Pelajaran Biologi Di MAN Kota Tasikmalaya
}

\author{
Nisha Nurul Oktaviani, Purwati Kuswarini Suprapto*, Romy Faisal Mustofa \\ Pendidikan Biologi, Fakultas Keguruan dan Ilmu Pendidikan, Universitas Siliwangi, Jl. Siliwangi No. 24, \\ Kota Tasikamalaya, Indonesia \\ *e-mail: purwatikuswarini@unsil.ac.id
}

Received: Januari 18, 2021

Accepted: April 30, 2021

Online Published: April 30, 2021

\begin{abstract}
The Relatinship Between Cognitive Flexibility and Problem Solving Skill in Biologi Subjects at MA Tasikmalaya City. Biology subjects are included in science subjects, while students have difficulty solving problems because they are less able to think flexibly when receiving new information. The purpose of this study was to determine the relationship between cognitive flexibility and problem solving skills (KPM) in biology subjects in class X MIA 1 MAN Kota Tasikmalaya. This research was conducted from October to November 2020. The research method used was correlational with a total population of 3 class X MIA students with a total of 86 students. Samples were taken by purposive sampling technique of 1 class (28 people). The data analysis technique used is a simple linear regression test. Based on the results of the study, it can be concluded that there is a relationship between cognitive flexibility and problem solving skills $(R=0.840 ; R 2=0.706)$. Has a relationship strength of 0.840 and a contribution of cognitive flexibility to problem solving skills by $70.6 \%$.
\end{abstract}

Keywords: biology subjects, cognitive flexibility, problem solving skills

\begin{abstract}
Abstrak: Hubungan Antara Fleksibilitas Kognitif Dengan Keterampilan Pemecahan Masalah Pada Mata Pelajaran Biologi Di MA Kota Tasikmalaya. Mata pelajaran biologi termasuk ke dalam mata pelajaran sains namun peserta didik kesulitan memecahkan masalah karena kurang bisa berpikir secara fleksibel saat menerima informasi baru. Tujuan penelitian ini adalah untuk mengetahui hubungan antara fleksibilitas kognitif dengan keterampilan pemecahan masalah (KPM) pada mata pelajaran biologi di kelas X MIA 1 MAN Kota Tasikmalaya. Penelitian ini dilaksanakan pada bulan oktober sampai bulan november 2020. Metode penelitian yang digunakan adalah korelasional dengan populasi seluruh peserta didik kelas X MIA sebanyak 3 kelas dengan jumlah peserta didik 86 orang. Sampel diambil dengan teknik purposive sampling sebanyak 1 kelas (28 orang). Teknik analisis data yang digunakan adalah uji regresi linier sederhana. Berdasarkan hasil penelitian dapat disimpulkan bahwa ada hubungan antara fleksibilitas kognitif dengan keterampilan pemecahan masalah $(\mathrm{R}=0,840 ; \mathrm{R} 2=0,706)$. Memiliki kekuatan hubungan sebesar 0,840 dan kontribusi dari fleksibilitas kognitif terhadap keterampilan pemecahan masalah sebesar $70.6 \%$.
\end{abstract}

Kata kunci: fleksibilitas kognitif, keterampilan pemecahan masalah, mata pelajaran biologi 


\section{PENDAHULUAN}

Pembelajaran dilakukan bertujuan untuk melatih kecakapan dan mendapatkan pengetahuan yang akan digunakan serta bermanfaat untuk kehidupan. Melatih kecakapan dan mendapat pengetahuan biasanya dilakukan secara bersamaan saat pembelajaran. Kecakapan yang dimaksud meliputi seluruh kecakapan yang bisa dilatih seperti berpikir, bicara, menghitung, menulis dan sebagainya. Pengetahuan digunakan untuk membantu menyelesaikan sebuah masalah, begitu pula dengan pengolahan pengetahuan yang dapat membantu menyelesaikan sebuah masalah. Pengetahuan memberikan bantuan yang positif terhadap pengembangan kecakapan, salah satu contohnya yaitu keterampilan pemecahan masalah.

Keterampilan pemecahan masalah sangat penting dimiliki seorang individu untuk menjalani kehidupan. Keterampilan pemecahan masalah atau problem solving skill adalah kemampuan mengolah informasi untuk mengatasi sebuah masalah secara logis. Problem solving sendiri berarti keterkaitan yang rumit antara kognitif, afektif dan proses perilaku untuk beradaptasi terhadap permintaan internal maupun eksternal ataupun tantangan (Heppner \& Baker, 1997). Ada juga yang mengartikan problem solving skill adalah proses kogntif secara menyeluruh dan rumit melibatkan meta-cognitive thinking, termasuk menentukan solusi yang paling efektif dan memutuskan solusi (Esen, 2018). Problem solving juga dapat berarti self-directed cognitive-behavioral process dimana seorang individu berupaya mencari solusi efektif dan adaptif untuk masalah yang spesifik (Demiris et al., 2010). Problem solving akan selalu melibatkan information-processing system untuk menyelesaikan tugas atau tantangan. Keterampilan pemecahan masalah saling berbanding lurus dengan kontrol amarah dan adaptasi sosial (Beyazsacli, 2016). Tingginya keterampilan pemecahan masalah menentukan seberapa sulit masalah yang dapat dipecahkan, bagi individu yang keterampilan pemecahan masalahnya tinggi sangat mungkin bagi individu tersebut menyelesaikan masalah yang tidak terstruktur (illstructured). Keterampilan pemecahan masalah yang baik biasanya diiringi dengan kemampuan berpikir tingkat tinggi yang baik.

Kemampuan berpikir tingkat tinggi atau Higher Order Thinking Skills (HOTS) bila dilihat dalam tingkatan kemampuan ranah kognitif taksonomi Bloom meliputi kemampuan menganalisis (C4), kemampuan mengevaluasi (C5) serta kemampuan untuk mencipta (C6). Tiga tingkatan tersebut akan digunakan sesuai dengan masalah yang dihadapi, misalnya untuk masalah yang menyediakan banyak solusi maka kemampuan mengevaluasi (C5) akan digunakan untuk mengevaluasi solusi-solusi yang ada lalu memilih solusi paling efektif dan efisien.

Saat mengaplikasikan keterampilan pemecahan masalah secara nyata, kemampuan berpikir dan proses pengolahan informasi akan selalu digunakan. Namun masalah kadang muncul dilingkungan baru dan dibutuhkan kemampuan adaptasi untuk memecahkannya, kemampuan adaptasi dalam keterampilan pemecahan masalah sering merujuk pada fleksibilitas kognitif.

Fleksibilits kognitif (Cognitive Flexibility) adalah kemampuan individu untuk beradaptasi dengan keadaan (situasi). Fleksibilitas kognitif menjadikan individu mengetahui manfaat dari menjadi fleksibel dan sadar akan adanya komunikasi alternatif untuk memecahkan suatu masalah dalam situasi yang baru (Martin \& Anderson, 1998). Fleksibilitas kognitif juga dapat berarti kemampuan adaptasi proses kognitif manusia untuk menghadapi kondisi baru dan tidak terduga di lingkungan (Cañas et al., 2006). Lalu secara umum dapat didefinisikan sebagai kemampuan untuk beralih diantara pemikiranpemikiran untuk merespon secara adaptif (Yu \& Lee, 2016). Fleksibilitas kognitif dapat 
merujuk pada bagaimana individu menyatakan pengetahuannya tentang tugas dan kemungkinan strategi yang terkait dengan tugas tersebut (Cañas et al., 2005). Fleksibilitas kognitif juga merujuk pada kemampuan anak untuk menggeneralisasi, memilih dan mengaplikasikan berbagai problem-solving strategies secara kreatif yang sesuai dengan tuntutan tugas belajar yang kompleks dan melibatkan kemampuan untuk merespon secara kreatif terhadap tuntutan tidak terduga dari lingkungan (Human \& Vogel, 2009). Fleksibilitas kognitif berperan dalam akuisisi pengetahuan (pemerolehan pengetahuan) (Spiro, Coulson, Feltovich, \& Anderson, 1988), juga memiliki peran dalam pengolahan pengetahuan. Fleksibilitas kognitif dapat mempengaruhi kemampuan adaptasi perilaku kognitif dan kemampuan mengingat (Taconnat et. al, 2009). Sehingga fleksibilitas kognitif sering sekali berkaitan dengan kemampuan berpikir.

Fleksibilitas kognitif berkontribusi dalam keterampilan pemecahan masalah sebagai bagian dari HOTS. HOTS seringkali melibatkan banyak informasi yang berkaitan dengan masalah untuk diproses agar dapat menemukan solusi, diperlukan penyesuaian informasi dengan lingkungan. Fleksibilitas kognitif membantu mengkontruksi pengetahuan yang ada dan menyesuaikan informasi tersebut dengan permasalahan yang baru. Berpikir secara HOTS sangat dibutuhkan di industri tenaga kerja, sehingga HOTS sering dilatih dalam pembelajaran di sekolah. Salah satu mata pelajaran yang melatih HOTS adalah mata pelajaran biologi.

Biologi merupakan ilmu pengetahuan yang bersumber dari kehidupan, oleh karena itu menjadi salah satu dari ilmu yang wajib dipelajari bagi peserta didik. Pada tingkat pendidikan SMP atau sederajat, ilmu biologi diajarkan pada mata pelajaran ilmu pengetahuan alam terpadu dan pada tingkat pendidikan SMA dan MA, biologi menjadi mata pelajaran tersendiri. Materi pembelajaran biologi akan semakin kompleks sejalan dengan semakin naiknya tingkatan sekolah, sehingga mengharuskan pemahaman yang baik untuk materi-materi sebelumnya. Lingkungan sosial baru, status baru dan tuntutan baru mengharuskan peserta didik untuk beradaptasi pada masa awal persekolahan di SMA atau MA. Walaupun MA memiliki jumlah mata pelajaran yang lebih banyak dari pada SMA, dan bersekolah dari hari senin sampai sabtu. Tapi secara umum mata pelajaran biologi yang di ajarkan di SMA atau MA sama, memiliki Kompetensi dasar yang sama dan memiliki banyak jam pelajaran biologi yang sama. MAN 2 Kota Tasikmalaya sendiri di pilih dengan alasan bahwa peneliti melakukan observasi yang cukup lama, sehingga mengetahui bagaimana cara guru biologi mengajar dan bagaimana peserta didik belajar biologi didalam kelas.

Peserta didik kelas $\mathrm{X}$ akan belajar sambil beradaptasi dengan situasi. Perbedaan dalam Informasi yang didapatkan saat belajar kadang tidak sepenuhnya sesuai dengan keadaan, menyebabkan perlunya penyesuaian informasi dan pengkajian informasi lebih lanjut untuk bisa diaplikasikan dengan baik. Penelitian dalam perkembangan pembelajaran biologi sering sekali dihubungkan dengan kehidupan sehari-hari, penelitian-penelitian tersebut meliputi model, pendekatan, media pembelajaran, perkembangan perilaku peserta didik dan lain sebagainya.

Walker et al. pada tahun 2002, melakukan penelitian tentang fleksibilitas kognitif dalam anagram problem solving pada mahasiswa native speaker bahasa inggris, hasil penelitian tersebut menyatakan bahwa fleksibilitas kognitif berkontribusi terhadap keterampilan pemecahan masalah sebagai pembangun solusi kreatif. Penelitian lainnya yang dilakukan Aygun Hanife Esen pada tahun 2018 tentang hubungan fleksibilitas kognitif dengan keterampilan pemecahan masalah interpersonal (the interpersonal problem solving skills) pada guru pra-jabatan (pre-service teacher), hasil penelitian 
menunjukan adanya hubungan fleksibilitas kognitif dengan keterampilan pemecahan masalah interpersonal yang baik, walau pun tidak terlalu tinggi. Penelitian-penelitian tersebut menunjukan kontribusi yang positif dari fleksibilitas kognitif terhadap keterampilan pemecahan masalah, namun jarang sekali ada yang membahasnya dalam ruang lingkup pembelajaran biologi tingkat SMA.

Berdasarkan uraian tersebut, penulis tertarik untuk melakukan penelitian tentang hubungan fleksibilitas kognitif dengan keterampilan pemecahan masalah pada mata pelajaran biologi di MAN 2 Kota Tasikmalaya. Harapannya dengan ditemukan hubungan antara fleksibilitas kognitif dengan keterampilan pemecahan masalah dapat membantu guru menentukan pendekatan dan model belajar yang tepat untuk meningkatkan kemampuan peserta didik, khususnya keterampilan pemecahan masalah pada mata pelajaran biologi. Sehingga peserta didik lebih memahami materi pelajaran biologi.

\section{METODE}

Metode penelitian yang digunakan dalam penelitian penelitian ini adalah korelasional. Penelitian ini dilakukan pada bulan november 2020. Variabel terikatnya adalah keterampilan pemecahan masalah dan variabel bebasnya adalah fleksibilitas kognitif. Populasi dalam penelitian ini adalah seluruh kelas X MIA di MA Kota Tasikmalaya pada tahun ajaran 2019/2020. Teknik sampel yang digunakan adalah purposive sampling dengan sampel kelas X MIA 1 dengan jumlah 28 peserta didik. Teknik pengumpulan data yang digunakan dalam penelitian ini adalah angket dan tes. Angket digunakan untuk mengumpulkan data fleksibilitas kognitif dan tes digunakan untuk pengambilan data keterampilan pemecahan masalah. Instrumen penelitian ini adalah angket CFI (Cognitive Flexibility Inventory yang dikembangkan oleh Dennis dan Vander Wal (2010). Berdasarkan uji validitas dan uji reliabilitas, dari 20 item pernyataan, 15 pernyatan dinyatakan valid dengan nilai koefisien Alpha Cronbach $=0,86$. Instrumen keterampilan pemecahan masalah diukur menggunakan soal yang dikembangkan dari stages of problem solving dari D,Zurilla dan Goldfried (1971), terdiri dari lima stage yaitu (1) general orientation, (2) problem definition, (3) generation of alternatives, (4) desicion making dan (5) verification. Berjumlah 4 soal untuk masingmasing indikator dengan nilai koefisien Alpha Cronbach $=0,95$. Data kemudian dianalisis untuk mengetahui hubungan fleksibilitas kognitif dengan keterampilan pemecahan masalah peserta didik X MIA 1 MA Negeri 2 Kota Tasikmalaya. Teknik analisis data yang digunakan adalah uji prasyarat dan uji hipotesis. Uji prasyarat meliputi uji normalitas kolmogorof smirnov dan uji linearitas, serta uji hipotesis menggunakan uji regresi linier sederhana.

\section{HASIL DAN PEMBAHASAN}

Penelitian yang berkenaan dengan hubungan antara fleksibilitas kognitif dengan keterampilan pemecahan masalah pada mata pelajaran biologi di kelas X MIA 1 MA Negeri 2 Kota Tasikmalaya dengan sampel 28 peserta didik. Pada penelitian ini data diperoleh dari tes dan nontes. Variabel bebas yaitu fleksibilitas kognitif (X) diukur menggunakan instrumen nontes berupa CFI (Cognitive Flexibility Inventory) yang berjumlah 15 pernyataan. Variabel terikat yaitu keterampilan pemecahan masalah (Y) diukur menggunakan instrumen tes berupa soal sebanyak 4 butir soal untuk setiap indikator.

Hasil analisis uji regresi linier sederhana dengan menggunakan software SPSS versi 23 for windows dapat dilihat pada Tabel 1 dan Tabel 2. 
Tabel 1. Hasil Perhitungan Regresi Linier Sederhana

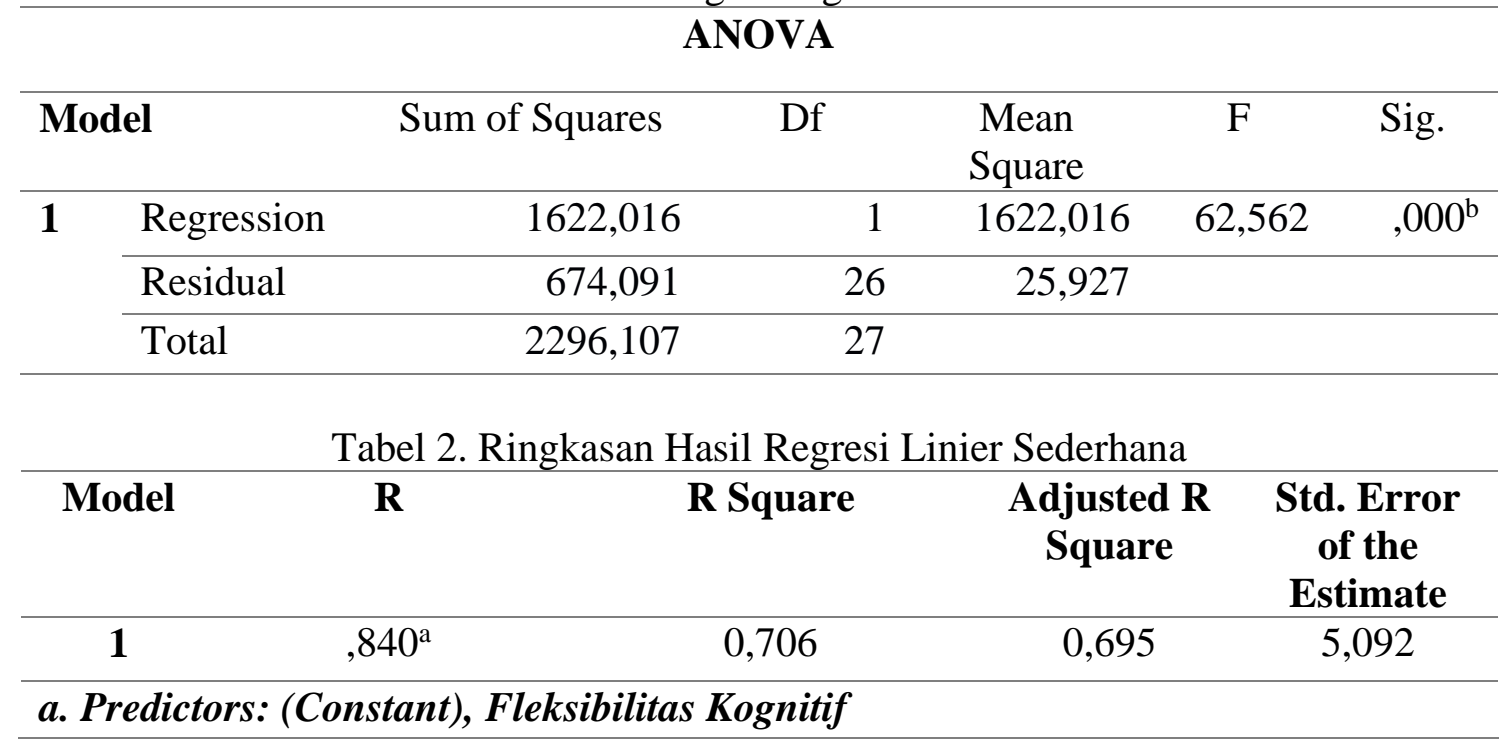

Berdasarkan hasil yang terdapat pada tabel diatas nilai signifikansi yang diperoleh sebesar 0,000 yang berarti ada korelasi antara fleksibilitas kognitif dengan keterampilan pemecahan masalah. Nilai koefisien korelasi (R) sebesar 0,840 dan nilai koefisien determinasi $\left(\mathrm{R}^{2}\right)$ sebesar 0,704 . Sehingga dapat disimpulkan bahwa variabel fleksibilitas kognitif memberikan kontribusi sebesar 70,4\% dan 29,6\% merupakan variabel lain yang tidak diteliti dalam penelitian ini.

Tabel 3. Koefisien Hasil Regresi Linier Sederhana

\begin{tabular}{|c|c|c|c|c|c|c|}
\hline & \multirow[t]{2}{*}{ Model } & \multicolumn{2}{|c|}{$\begin{array}{l}\text { Unstandardized } \\
\text { Coefficients }\end{array}$} & \multirow{2}{*}{$\begin{array}{c}\text { Standardized } \\
\text { Coefficients }\end{array}$} & \multirow[t]{2}{*}{$\mathbf{t}$} & \multirow[t]{2}{*}{ Sig. } \\
\hline & & B & $\begin{array}{l}\text { Std. } \\
\text { Error }\end{array}$ & & & \\
\hline \multirow[t]{2}{*}{1} & (Constant) & $-37,304$ & 6,767 & & $-5,512$ & 0,000 \\
\hline & $\begin{array}{c}\text { Fleksibilitas } \\
\text { Kognitif }\end{array}$ & 0,703 & 0,089 & 0,840 & 7,910 & 0,000 \\
\hline
\end{tabular}

a. Dependent Variable: Keterampilan Pemecahan Masalah

Berdasarkan tabel diatas dapat diketahui persamaan regresi Ý = a-bx. Nilai a adalah $-37,304$ dan nilai $b$ adalah0,703. Sehingga persamaan regresi yang diperoleh adalah $Y ́=$ $(-37,304)+0,703 x$.

Hasil dari uji hipotesis dengan menggunakan uji regresi linier sederhana menunjukan terdapat hubungan antara fleksibilitas kognitif dengan keterampilan pemecahan masalah yang ditandai dengan signifikansi 0,000 dan derajat korelasi antara fleksibilitas kognitif dan keterampilan pemecahan masalah sebesar 0,840 (pearson correlation) yang menunjukan derajat korelasi termasuk ke dalam kategori kuat. Sehingga diketahui bahwa terdapat hubungan yang positif sebesar 0,840 antara fleksibilitas kognitif dengan keterampilan pemecahan masalah.

Adanya hubungan yang kuat antara fleksibilitas kognitif dengan keterampilan pemecahan masalah peserta didik pada mata pelajaran biologi serta adanya kontribusi fleksibilitas kognitif terhadap keterampilan pemecahan masalah, tidak terlepas dari 
peranan variabel tersebut. Nilai fleksibilitas kognitif yang tinggi akan memungkinkan peserta didik untuk menemukan berbagai solusi alternatif dalam menyelesaikan masalah dan tidak terikat dengan solusi dan cara-cara yang sudah ada menjadikan peserta didik lebih terbuka dengan kemungkinan-kemungkinan yang terjadi saat mencoba menyelesaikan sebuah masalah. Sebaliknya, bila nilai fleksibilitas kognitifnya rendah maka akan menyebabkan kegagalan untuk menyadari bahwa masalah yang dihadapi merupakan masalah baru, dan gagal menyadari bahwa masalah terjadi pada situasi yang unik atau berbeda dengan sebelumnya (Strager dan Leithwood, 1988).

Pemecahan masalah semakin diakui sebagai aspek penting dari pendidikan sains, baik sebagai sarana untuk memfasilitasi pembelajaran dan sebagai latihan dalam memperoleh keterampilan pemecahan masalah itu sendiri (Garrett, 1986). Begitu juga dengan biologi yang termasuk kedalam sains. Pada mata pelajaran biologi peserta didik dituntut untuk mampu berpikir secara ilmiah dan belajar dengan dihadapkan pada berbagai permasalahan yang terjadi sehingga keterampilan pemecahan masalah sangat dilatih, maka fleksibilitas kognitif dapat membantu peningkatan keterampilan pemecahan masalah sehingga pembelajaran berjalan dengan baik.

Fleksibilitas kognitif sangat berkaitan dengan indikator-indikator yang dipakai dalam pengukuran keterampilan pemecahan masalah pada penelitian ini. Indikator tertama yaitu general orientation, merupakan tahap observasi masalah. Pada tahap ini peserta didik akan menilai mana informasi yang penting dan faktor-faktor apa saja yang menyebabkan permasalahan itu terjadi. Fleksibilitas kognitif membantu peserta didik untuk lebih memperhatikan informasi-informasi terkait masalah tersebut. Fleksibilitas kognitif sangat bergantung pada attentional processes (proses yang melibatkan perhatiaan) (Cañas, Fajardo, \& Salmerón, 2005). Jadi bila fleksibilitasnya tinggi berarti peserta didik tersebut memiliki attentional processes yang baik sehingga mampu memperhatikan informasi-informasi dalam masalah dengan baik. Tidak hanya pada attentional processes saja, fleksibilitas kognitif juga membantu peserta didik untuk menerima fakta yang terjadi sehingga mereka sadar bahwa masalah tersebut bisa diatasi. Instrumen Fleksibilitas kognitif CFI mengukur kencenderungan utuk menyadari bahwa situasi sulit sebagai situasi yang mampu dikontrol (Dennis dan Vander Wal, 2010). Sehingga peserta didik tidak menyerah untuk menyelesaikan permasalahan karena masalah yang dihadapi merupakan masalah yang masih terkontrol, dan mungkin untuk dipecahkan. Pada indikator generation of alternatives dan decision making, fleksibilitas kognitif berperan sebagai jalan agar tidak membatasi tindakan yang dilakukan untuk memenuhi kedua indikator tersebut.

Pada indikator generation of alternatives, fleksibilitas kognitif akan membantu menyediakan banyak altenatif solusi. Pada indikator decision making, fleksibilitas kognitif akan membantu peserta didik untuk memikirkan kemungkinan kemungkinan yang akan terjadi sebelum keputusan pengambilan solusi diambil. Fleksibilitas kognitif termasuk kepada fluid intelligence, yang memperbolehkan untuk menghalangi solusi paling dominan untuk langsung dipilih dan mempertimbangkan terlebih dahulu solusi anternatif yang lain (Silver, Hughes, Bornstein dan Beversdorf, 2004). Fleksibilitas kognitif juga dapat diartikan sebagai kemampuan untuk menentukan langkah-langkah pemecahan sebuah masalah dan sebagai kemampuan untuk memilih jalan yang terbaik dengan mengevaluasi semua pilihan terhadap situasi baru dan situasi yang mungkin terjadi (Esen, 2018).

Level fleksibilitas kognitif dan keterampilan pemecahan masalah saling berhubungan (Esen, 2018). Fleksibilitas kognitif memberikan kontribusi terhadap 
keterampilan pemecahan masalah sebanyak 70,6\%. Oleh karena itu erat hubungannya antara fleksibilitas kognitif terhadap keterampilan pemecahan masalah. Fleksibilitas kognitif dilihat sebagai kemampuan penggunaan informasi ketika keterampilan pemecahan masalah sedang dilatih dan digunakan. Hal ini disimpulkan berdasarkan pengertian dari fleksibilitas kognitif itu sendiri. Fleksibilitas kognitif diartikan sebagai kemampuan berpikir pada berbagai sudut pandang untuk menggunakan pengetahuan di masa mendatang yang kemunkinan akan dihadapi oleh individu (Spiro, Feltevich, Jacobson dan Coulson, 1991).

Penelitian yang telah dilakukan sebelumnya menunjukan bahwa adanya hubungan antara fleksibilitas kognitif dengan problem solving. Penelitian Theboom, Beersma, dan Vianen (2016) menunjukan bahwa solution-focused coaching questions (soal latihan yang berfokus terhadap solusi) memiliki hubungan yang lebih baik $(\mathrm{M}=$ $5,13, \mathrm{SD}=1,71$ ), daripada problem-focused coaching questions (soal latihan yang berfokus terhadap masalah) $(\mathrm{M}=4,04, \mathrm{SD}=1,58)$.

Penelitian lainnya yang dilakukan oleh Esen-Aygun (2018) menunjukan bahwa gender dan pendidikan maternal memiliki pengaruh terhadap fleksibilitas kognitif. Selain itu pada penelitian ini juga menjelaskan hubungan antara fleksibilitas kognitif dengan interpersonal problem solving abilities (kemampuan pemecahan masalah interpersonal), terdapat hubungan positif yang lemah antara fleksibilitas kognitif dengan interpersonal problem solving abilities $(\mathrm{r}=.41)$. namun terdapat hubungan positif yang kuat antara alternatif sub-faktor dalam fleksibilitas kognitif dengan sub-faktor constructive problemsolving $(\mathrm{r}=.74)$. Jadi dapat disimpulakan bahwa fleksibilitas kognitif berhubungan positif yang kuat dengan indikator tertentu dan berhubungan positif yang lemah dengan yang lainnya dalam problem solving skills.

Penelitian-penelitian tersebut menunjukan bahwa fokus soal dan indikator yang dinilai dalam problem-solving skills juga dapat berpengaruh terhadap hubungan antara fleksibilitas kognitif dengan problem solving. Sehingga dimungkinkan terdapat perbedaan seberapa besar konstribusi fleksibilitas kognitif terhadap keterampilan pemecahan masalah tergantung pada indikator yang dinilai.

\section{SIMPULAN}

Berdasarkan hasil analisis data yang diperoleh, menunjukan bahwa terdapat hubungan antara fleksibilitas kognitif dengan keterampilan pemecahan masalah pada mata pelajaran biologi di MA Negeri 2 Kota Tasikmalaya dengan kategori hubungan kuat. Arah hubungan yang positif antara fleksibilitas kogntif dengan keterampilan pemecahan masalah, berarti semakin besarnya nilai fleksibilitas kognitif akan semakin tinggi juga kemampuan pemecahan masalah individu tersebut. Hasil penelitian juga menunjukan bahwa pengunaan instrumen untuk pengukuran dapat mempengaruhi kekuatan hubungan antara fleksibilitas kognitif dengan keterampilan pemecahan masalah. Saran untuk penelitian-penelitian selanjutnya, agar lebih memperhatikan penggunaan instrumeninstrumen yang digunakan untuk mengukur fleksibilitas kognitif dengan keterampilan pemecahan masalah.

\section{DAFTAR RUJUKAN}

Beyazsacli, Mehmet. (2016). Relationship Between Problem Solving Skills and Academic Achievement. Anthropologist, 25(3), 288-293.

Canas, J. J.. A. Antolí, I. Fajardo dan Salmerón. (2005). Cognitive Inflexibility and The Development and Use of Strategies for Solving Complex Dynamic Problems: Effects 
of Different Types of Training. Theoretical Issues in Ergonomics Science, 6(1), 95108.

Canas, J. J.. A. Inmaculada Fajardo dan Ladislao Salmerón. (2006). Cognitive Flexibility. Demiris, G., Parker Oliver, D., Washington, K., Thomas Fruehling, L., HaggartyRobbins, D., Dooorenbos, A. ... Berry, D. (2010). A Problem Solving Inventory For Hospice Caregivers: a Pilot Study. Journal Of Palliative Medicine, 13(8), 10051011.

Dennis, John P. dan Jillon S. Vander Wal. (2010). The Cognitive Flexibility Inventory: Instrumen Development and Estimates of Reability and Validity. Cogn Ther Re, 34, 241-253.

D'Zurilla, T. J. dan Goldfried, M. R. (1971). Problem Solving And Behavior Modification. Journal Of Abnormal Psychology. 78(1), 107-126.

Esen-Aygun, H. (2018). The Relationship Between Pre-Service Teachers' Cognitive Flexibility and Interpersonal Problem Solving Skills. Eurasian Journal of Educational Research, 77, 105-128.

Garrett, R. M. (1986). Problem-Solving in Science Education. Studies in Science Education, 13, 70-95.

Heppner, P. P., dan Baker, Charles E. (1997). Applications Of The Problem Solving Inventory. Measurement And Evaluation In Counseling And Development, 29.

Human, Salomé dan Vogel. (2009). The Use Of Mediation As a Strategy To Enhance The Development Of Cognitive Flexibility In Self-Regulated Learning. Education As Changes, 8(1), 3-27.

Martin, Matthe M., dan Anderson. Carolyn M..(1998). The Cognitive Flexibility Scale : Three validity studies. Communication Reports, 11(1), 1-9.

Silver, Jennifer A.. John D. Hughes, Robert A. Bornstein dan David Q. Beversdorf. (2004). Effect of Anxiolytics on Cognitive Flexibility in Problem Solving. Cog Behav Neurol, 17(2).

Spiro, R. J., Coulson, R. L., Feltovich, P. J., dan Anderson, D. K. (1988). Cognitive Flexibility Theory: Advance Knowledge Acquisition In Ill-Structured Domains. In The Tenth Annual Conference Of The Cognitive Science Society. Hillsdale, NJ: Lawrence Erlbaum Associates.

Spiro, R. J., Feltovich, P. J., Jacobson, M. J., dan Coulson, R. L. (1991). Cognitive Flexibility, Constructivism, and Hypertext: Random access instruction for advanced knowledge acquisition in ill-structured domains. Educational Technology, 31(5), 24-33.

Taconnat, Laurence et.al. (2009). Ageing and Organisation Strategi in Free Recall: The Role of Cognitive Flexibility. European Journal of Cognitive Psychology, 21 (2/3), 347-365.

Theeboom, T., Beersma, B., dan Van Vianen, A. E. (2016). The differential effects of solution-focused and problem-focused coaching questions on the affect, attentional control and cognitive flexibility of undergraduate students experiencing studyrelated stress. The Journal of Positive Psychology, Vol. 11, No. 5, 460-469.

Yu, Yunhong dan Tatia M. C. Lee. (2016). Cognitive Flexibility and Changes in Hopelessness across time : A Moderation Hypothesis. Applied Neuropsychology : Adult.

Walker, Matthew P. et.al. (2002). Cognitive Flexibility across the sleep-wake cycle: REM-sleep Enchancement of Anagram Problem Solving. Elvisier : Cognitive Brain Research, 14 (2002), 317-324. 